\title{
SIMULAÇÃO DO DESLOCAMENTO DO FORNO DE IGNIÇÃO NA SINTERIZAÇÃO DE MINÉRIO DE FERRO COM RECIRCULAÇÃO DOS GASES DE SAÍDA*
}

Vagner Silva Guilherme ${ }^{1}$ Jose Adilson de Castro ${ }^{1}$

\begin{abstract}
Resumo
$\mathrm{Na}$ busca de novas tecnologias para o processo de sinterização de minério de ferro, a recirculação dos gases de saída do processo podem proporcionar algumas vantagens em relação ao processo convencional. Para tal estudo, foi utilizado um modelo multi-fásico de sinterização para a avaliação da recirculação dos gases de saída do processo. Foram analisados cinco casos de recirculação dos gases de saída, do processo de sinterização, visando, sempre uma operação estável do processo. Os resultados de simulação indicam alargamento da frente de combustão com a recirculação dos gases de saída e a possibilidade da redução do consumo do combustível sólido. Como resultado, houve aumento da fração de cálcio-silicatos, proporcionando melhoria da redutibilidade do sínter, além da redução da emissão de $\mathrm{CO}_{2}$ e PCDD/Fs na máquina de sínter.
\end{abstract}

Palavras-chave: Sinterização; Recirculação de gases; Simulação computacional.

\section{DISPLACEMENT OF THE INGNITION FURNACE IN THE IRON ORE SINTERING WITH RE-CIRCULATION OF WASTE GASES}

\begin{abstract}
In search of new technologies for the iron ore sintering process, the re-circulation of waste gases in the process can provide some advantages in relation to the conventional process. For such study, a sintering multi-phase model was used for the assessment of the recirculation of waste gases in the process. Five cases of re-circulation of waste gases in the sintering process were analyzed, always aiming at a stable operation in the process. The results of the simulation indicate an enlargement of the combustion front with the recirculation of the waste gases and the possibility of existing a reduction of the solid fuel consumption. As a result, there was an increase of the calcium- silicate fraction, providing a sinter reducibility improvement, apart from the reduction of the emission of $\mathrm{CO}_{2}$ and $\mathrm{PCDD} / \mathrm{Fs}$ in the sinter machine.
\end{abstract}

Keywords: Sintering; Gas re-circulation; Computational simulation.

1 Programa de Pós Graduação Engenharia Metalúrgica, UFF, Pólo de Volta Redonda, RJ, Brasil.

* Contribuição técnica ao 44ํ Seminário de Redução de Minério de Ferro e Matérias-primas,

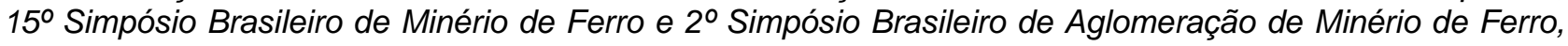
15 a 18 de setembro de 2014, Belo Horizonte, MG, Brasil. 


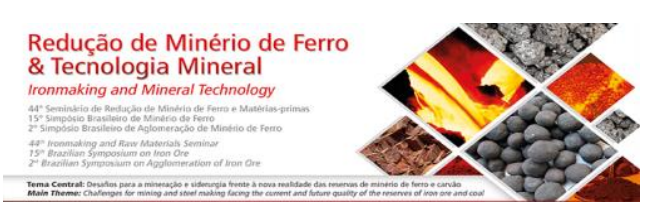

\section{INTRODUÇÃO}

O processo de sinterização é usado para fundir parcialmente e agregar os finos de minério de ferro, com a finalidade de produzir sínter para o processo de redução em altos fornos. A resistência mecânica do agregado dependerá da quantidade e tipo de material fundido entre as partículas [1].

O processo é complexo e envolve vários fenômenos físicos e químicos tais como, transferência de calor, massa e momentum. Estes fenômenos ocorrem simultaneamente aumentando consideravelmente a complexidade da análise e controle do processo [2].

O gás produzido na sinterização pode ser recirculado visando maior eficiência térmica e controle de poluição. O processo é realizado em uma esteira móvel, onde a mistura de minério (sinter feed), finos de coque, calcário e água é continuamente carregada formando um denso leito. Nos primeiros metros da esteira, os queimadores a gás natural e ar promovem a ignição. $O$ ar é então succionado através do leito poroso e direcionado para as caixas de vento localizadas abaixo da esteira rolante. O contato do ar quente com a moinha de coque da mistura promove a combustão deste gerando energia para a propagação da chamada frente de combustão, formando uma fina zona que se propaga pelo leito, à medida que a esteira se move. Várias reações químicas e transformações de fases ocorrem no interior do leito, parte do material se torna pastoso tornando-se novamente sólido ao trocar calor com o gás frio que esta sendo succionado [3].

A recirculação dos gases gerados no processo pode ser uma técnica alternativa, capaz de ampliar a frente de combustão e diminuir o consumo de finos de coque proporcionando melhores propriedades ao sínter. O presente trabalho buscou verificar se o alongamento de esteira (aumento de três caixas de vento) junto com a recirculação dos gases de saída (injeção dos gases de saída na região das três primeiras caixas de vento) confere melhores propriedades físicas e mecanicas ao sínter. Para esse estudo, foi utilizado o modelo computacional para simulação do processo de sinterização de minério de ferro [2]. Uma visão esquemática, do processo de sinterização com o conceito de recirculação dos gases de saída e alongamento da esteira, é apresentada na Figura 1.

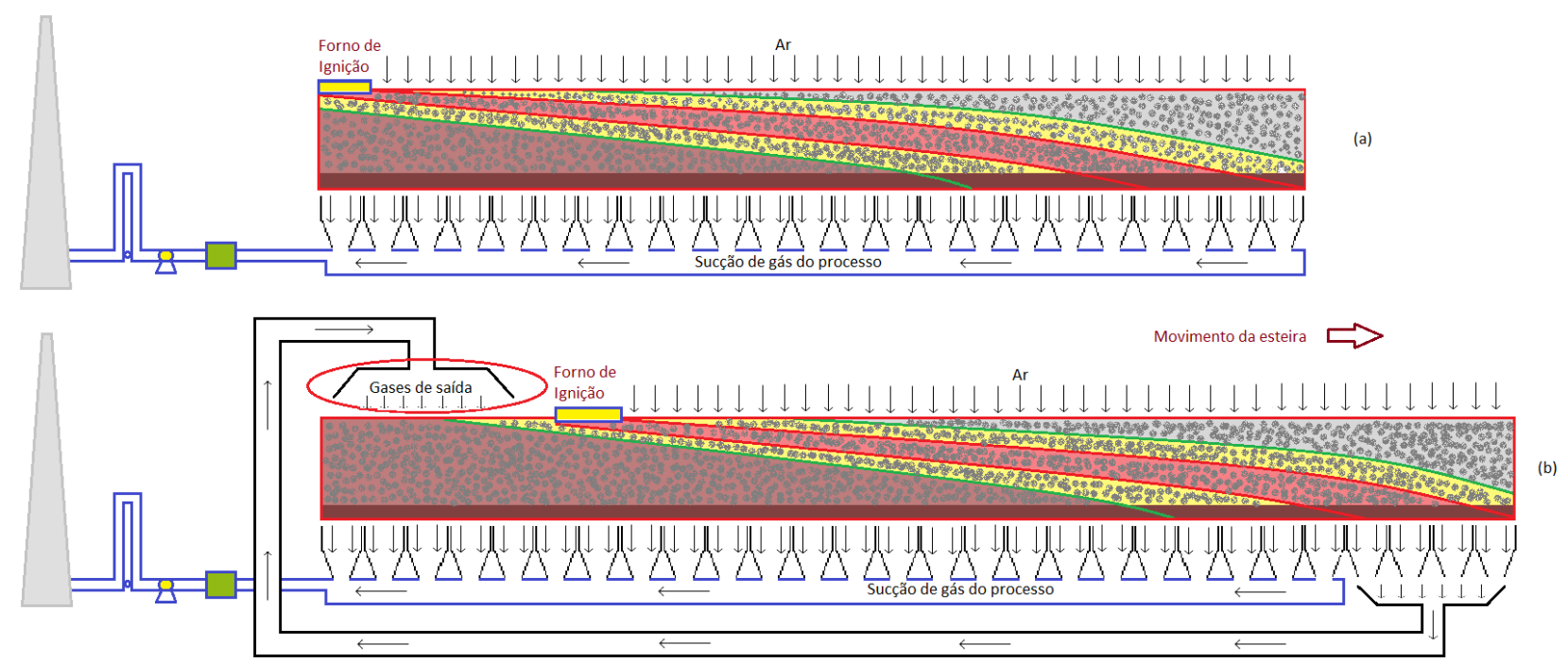

Figura 1: (a) Leito de sinterização; (b) Leito de sinterização com o princípio de recirculação dos gases de saída.

* Contribuição técnica ao 44ํ Seminário de Redução de Minério de Ferro e Matérias-primas, 15오 Simpósio Brasileiro de Minério de Ferro e 2o Simpósio Brasileiro de Aglomeração de Minério de Ferro, 15 a 18 de setembro de 2014, Belo Horizonte, MG, Brasil. 


\section{MODELAMENTO MATEMÁTICO}

Através da discretização das equações de transporte, utilizando o método de volumes finitos [4], podemos realizar simulações para previsão e caracterização de processos. 0 modelo consiste em descrever os fenômenos que ocorrem no interior do leito de sinterização de minério de ferro num sistema de duas fases que interagem entre si, transferindo momentum, massa e energia. Neste modelo foram calculados diferentes condições de operação para avaliar a qualidade do produto. Os fenômenos de transferência de momentum, energia e espécies químicas para cada fase envolvida no interior do leito foi representada pela Equação 1 (Equação geral de transporte). Nesta equação, o $1^{\text {o }}$ termo do lado esquerdo representa o termo transiente e o segundo quantifica a convecção, enquanto o $1^{\circ}$ termo do lado direito é a contribuição devido à difusão e o segundo agrupa os chamados termos fontes.

$$
\frac{\partial\left(\rho_{i} \varepsilon_{i} \phi_{i, k}\right)}{\partial t}+\operatorname{div}\left(\rho_{i} \varepsilon_{i} \vec{V}_{i} \phi_{i, k}\right)=\operatorname{div}\left(\Gamma_{\phi_{i, k}} \operatorname{grad}\left(\phi_{i, k}\right)\right)+S_{\phi_{i, k}}
$$

A Equação 1 sintetiza o balanço de todas as grandezas listadas na Tab. 1, em que os índices $i$ referem-se às fases e $\mathrm{K}$, às variáveis envolvidas no balanço, como: espécies químicas pertencentes à fase $i$, componentes de velocidades $(u)$ e entalpias $(H)$. $\rho$ e $\varepsilon$ representam as massas específicas e frações volumétricas das fases, respectivamente, enquanto $\Gamma$ é a difusividade efetiva, que pode representar viscosidade dinâmica, para 0 caso das equações de momentum, difusividades térmicas quando se tratam das equações de entalpia ou difusividade molecular para as equações de balanço de espécies químicas [5].

A Tabela 1 lista todas as espécies químicas e parâmetros calculados pelo modelo matemático. Por uma questão de simplificação das equações de momentum e energia, todas as fases sólidas e líquidas foram consideradas como uma única fase chamada sólida ou fase condensada. Esta suposição é justificada devido ao movimento das fases líquidas serem similar ao movimento das fases sólidas, no entanto, as espécies químicas destas fases são individualmente tomadas em consideração [6].

Tabela 1: Fases e espécies químicas consideradas no modelo do processo de sinterização.

\begin{tabular}{|c|c|c|c|}
\hline & & & Equações da fase gás \\
\hline \multirow{3}{*}{ Gás } & Momentum & \multicolumn{2}{|c|}{$\mathrm{u}_{1, \mathrm{~g}}, \mathrm{u}_{2, \mathrm{~g}}, \mathrm{u}_{3, \mathrm{~g}}, \mathrm{P}_{\mathrm{g}}, \varepsilon_{\mathrm{g}}$} \\
\hline & Energia & \multicolumn{2}{|c|}{$\mathrm{h}_{\mathrm{g}}$} \\
\hline & $\begin{array}{l}\text { Espécie } \\
\text { química }\end{array}$ & \multicolumn{2}{|c|}{$\mathrm{N}_{2}, \mathrm{O}_{2}, \mathrm{CO}, \mathrm{CO}_{2}, \mathrm{H}_{2} \mathrm{O}, \mathrm{H}_{2}, \mathrm{SiO}, \mathrm{SO}_{2}, \mathrm{CH}_{4}, \mathrm{C}_{2} \mathrm{H}_{6}, \mathrm{C}_{3} \mathrm{H}_{8}, \mathrm{C}_{4} \mathrm{H}_{10}$} \\
\hline \multirow{9}{*}{ Sólida } & & \multicolumn{2}{|c|}{ Equações da fase sólida } \\
\hline & Momentum & \multicolumn{2}{|c|}{$\mathrm{u}_{1, \mathrm{~s}}, \mathrm{u}_{2, \mathrm{~s}}, \mathrm{u}_{3, \mathrm{~s}}, \mathrm{P}_{\mathrm{s}}, \boldsymbol{\varepsilon}_{\mathrm{s}}$} \\
\hline & Energia & \multicolumn{2}{|c|}{$\mathrm{h}_{\mathrm{s}}$} \\
\hline & \multirow{6}{*}{$\begin{array}{l}\text { Espécie } \\
\text { química }\end{array}$} & Coque & $\mathrm{C}$, Volatiles, $\mathrm{H}_{2} \mathrm{O}, \mathrm{Al}_{2} \mathrm{O}_{3}, \mathrm{SiO}_{2}, \mathrm{MnO}, \mathrm{MgO}, \mathrm{CaO}, \mathrm{FeS}, \mathrm{P}_{2} \mathrm{O}_{5}, \mathrm{~K}_{2} \mathrm{O}, \mathrm{Na}_{2} \mathrm{O}, \mathrm{S}_{2}$ \\
\hline & & $\begin{array}{l}\text { Minério de } \\
\text { ferro }\end{array}$ & $\begin{array}{l}\mathrm{Fe}_{2} \mathrm{O}_{3}, \mathrm{Fe}_{3} \mathrm{O}_{4}, \mathrm{FeO}, \mathrm{Fe}, \mathrm{H}_{2} \mathrm{O}, \mathrm{Al}_{2} \mathrm{O}_{3}, \mathrm{SiO}_{2}, \mathrm{MnO}, \mathrm{MgO}, \mathrm{CaO}, \mathrm{FeS}, \mathrm{P}_{2} \mathrm{O}_{5}, \mathrm{~K}_{2} \mathrm{O} \text {, } \\
\mathrm{Na}_{2} \mathrm{O}\end{array}$ \\
\hline & & $\begin{array}{l}\text { Sínter de } \\
\text { retorno }\end{array}$ & $\begin{array}{l}\mathrm{Fe}_{2} \mathrm{O}_{3}, \mathrm{Fe}_{3} \mathrm{O}_{4}, \mathrm{FeO}, \mathrm{Fe}, \mathrm{H}_{2} \mathrm{O}, \mathrm{Al}_{2} \mathrm{O}_{3}, \mathrm{SiO}_{2}, \mathrm{MnO}, \mathrm{MgO}, \mathrm{CaO}, \mathrm{FeS}, \mathrm{P}_{2} \mathrm{O}_{5}, \mathrm{~K}_{2} \mathrm{O} \text {, } \\
\mathrm{Na}_{2} \mathrm{O}, \mathrm{Ca}_{2} \mathrm{Fe}_{3} \mathrm{O}_{5}, \mathrm{Al}_{2} \mathrm{MgO}_{4}\end{array}$ \\
\hline & & $\begin{array}{l}\text { Materiais } \\
\text { fundidos }\end{array}$ & $\begin{array}{l}\mathrm{Fe}_{2} \mathrm{O}_{3}, \mathrm{Fe}_{3} \mathrm{O}_{4}, \mathrm{FeO}, \mathrm{Fe}, \mathrm{H}_{2} \mathrm{O}, \mathrm{Al}_{2} \mathrm{O}_{3}, \mathrm{SiO}_{2}, \mathrm{MnO}, \mathrm{MgO}, \mathrm{CaO}, \mathrm{FeS}, \mathrm{P}_{2} \mathrm{O}_{5}, \mathrm{~K}_{2} \mathrm{O} \text {, } \\
\mathrm{Na}_{2} \mathrm{O}, \mathrm{Ca}_{2} \mathrm{Fe}_{3} \mathrm{O}_{5}, \mathrm{Al}_{2} \mathrm{MgO}_{4}\end{array}$ \\
\hline & & Fundentes & $\mathrm{CaO}, \mathrm{H}_{2} \mathrm{O}, \mathrm{Al}_{2} \mathrm{O}_{3}, \mathrm{SiO}_{2}, \mathrm{MnO}, \mathrm{MgO}, \mathrm{TiO}_{2}$ \\
\hline & & $\begin{array}{l}\text { Torta de } \\
\text { Sínter }\end{array}$ & $\begin{array}{l}\mathrm{Fe}_{2} \mathrm{O}_{3}, \mathrm{Fe}_{3} \mathrm{O}_{4}, \mathrm{FeO}, \mathrm{Fe}, \mathrm{H}_{2} \mathrm{O}, \mathrm{Al}_{2} \mathrm{O}_{3}, \mathrm{SiO}_{2}, \mathrm{MnO}, \mathrm{MgO}, \mathrm{CaO}, \mathrm{FeS}, \mathrm{P}_{2} \mathrm{O}_{5}, \mathrm{~K}_{2} \mathrm{O} \text {, } \\
\mathrm{Na}_{2} \mathrm{O}, \mathrm{Ca}_{2} \mathrm{Fe}_{3} \mathrm{O}_{5}, \mathrm{Al}_{2} \mathrm{MgO}_{4}\end{array}$ \\
\hline
\end{tabular}

* Contribuição técnica ao 44ํ Seminário de Redução de Minério de Ferro e Matérias-primas, $15^{\circ}$ Simpósio Brasileiro de Minério de Ferro e $2^{\circ}$ Simpósio Brasileiro de Aglomeração de Minério de Ferro, 15 a 18 de setembro de 2014, Belo Horizonte, MG, Brasil. 
conceito de interação das fases é mostrado através das setas na Figura 2. Esses componentes sofrem transformações durante o processo de sinterização.

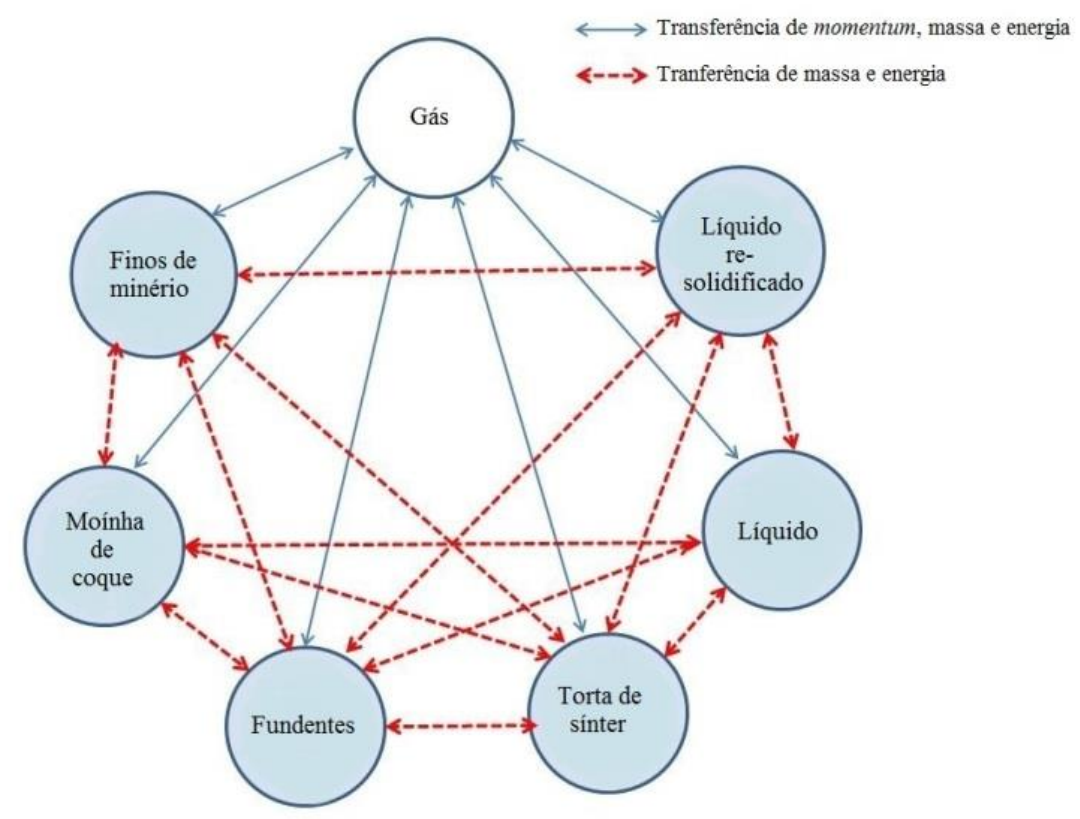

Figura 2: Interação entre momentum, energia e química das fases no modelo matemático.

\section{RESULTADOS E DISCUSSÃO}

Foi utilizado um caso base baseado em um conjunto de dados industriais e posteriormente sete novos cenários de operação foram calculados (utilizando uma esteira de maior comprimento). Os resultados de simulação apresentaram operações estáveis indicados pelo fechamento do balanço de massa (erro < 0,01) e de condições operacionais. O principal objetivo da escolha de novos cenários é comparar novas possibilidades às condições atuais de operação do processo. A Figura 3 apresenta as temperaturas calculadas na parte inferior do leito de sinterização, ou seja, na interface do leito com a esteira. Foram feitas as seguintes considerações nas simulações:

- Cenário-base: condição de operação de uma planta industrial de alta produtividade (esteira com 23 caixas de vento);

- Cenário 1: condição de operação de uma planta industrial de alta produtividade (esteira com 26 caixas de vento);

- Cenário 2: deslocamento da forno de ignição para 4 caixa de vento (esteira com 26 caixas de vento)

- Cenário 3: mesma configuração do cenário 2 porém com recirculação dos gases de saída com temperatura de $\sim 100^{\circ} \mathrm{C}$ na região das três primeiras caixas de vento.

- Cenário 4: mesma configuração do cenário 2 porém com recirculação dos gases de saída com temperatura de $\sim 200^{\circ} \mathrm{C}$ na região das três primeiras caixas de vento.

- Cenário 5: mesma configuração do cenário 2 porém com recirculação dos gases de saída com temperatura de $\sim 300^{\circ} \mathrm{C}$ na região das três primeiras caixas de vento.

- Cenário 6: mesma configuração do cenário 2 porém com recirculação dos gases de saída com temperatura de $\sim 400^{\circ} \mathrm{C}$ na região das três primeiras caixas de vento.

- Cenário 7: mesma configuração do cenário 2 porém com recirculação dos gases de saída com temperatura de $\sim 500^{\circ} \mathrm{C}$ na região das três primeiras caixas de vento.

* Contribuição técnica ao 44ํ Seminário de Redução de Minério de Ferro e Matérias-primas, 15 Simpósio Brasileiro de Minério de Ferro e 2 Simpósio Brasileiro de Aglomeração de Minério de Ferro, 15 a 18 de setembro de 2014, Belo Horizonte, MG, Brasil. 
$\mathrm{Na}$ Tabela 2, podemos observar alguns resultados obtidos com as simulações em cada cenário. Os resultados mostram que não ocorreu alteração na produtividade da máquina de sínter com a recirculação dos gases de saída, fato esperado, pois foi mantido o leito com as mesmas dimensões em todos os cenários [5]. Em relação ao consumo previsto de combustível sólido também foi mantido, assim como Guilherme et al. [5], existe a possibilidade de diminuirmos a quantidade de combustível solido ou ainda utilizarmos um de qualidade inferior, porém isso não foi abordado nas simulações

Tabela 2. Resultados obtidos com as Simulações.

\begin{tabular}{|c|r|r|r|r|r|r|r|r|}
\hline Parâmetros & \multicolumn{1}{c|}{$\begin{array}{c}\text { Cenário } \\
\text { Base }\end{array}$} & Cenário 1 & Cenário 2 & Cenário 3 & Cenário 4 & Cenário 5 & Cenário 6 & Cenário 7 \\
\hline Produtividade (t/h) & 817 & 817 & 817 & 817 & 817 & 817 & 817 & 817 \\
\hline $\begin{array}{c}\text { Combustível Sólido } \\
\text { (kg/tsínter) }\end{array}$ & 40,41 & 40,42 & 40,42 & 40,42 & 40,42 & 40,42 & 40,42 & 40,42 \\
\hline Calcio-Ferrita (\%) & 8,76 & 9,17 & 10,06 & 10,1 & 10,18 & 10,66 & 10,96 & 11,32 \\
\hline$\% \mathrm{CO}_{2}$ gás de saída & 13,03 & 11,75 & 11,75 & 12,48 & 12,48 & 12,45 & 12,49 & 12,5 \\
\hline $\mathrm{PCDD} / \mathrm{Fs}\left(\mathrm{ng} / \mathrm{Nm}^{3}\right.$ ) & 471 & 435 & 444 & 443,2 & 440,7 & 440 & 437 & 437 \\
\hline
\end{tabular}

Outro ponto importante observado foi a formação de cálcio-ferrita no processo. O modelo estima o valor de cálcio-ferrita através do diagrama de equilíbrio, no qual se baseia no histório térmico do material [7]. Quanto maior o tempo de residência do material a uma elevada temperatura, maior a formação de cálcio-ferrita.

Em relação à quantidade de $\mathrm{CO}_{2}$ no gás de saída, percebeu-se que através dessa técnica de recirculação de gases foi possível reduzir os níveis de emissão. Fato de estrema importância nos dias atuais devido à preservação ambiental, onde a redução da emissão de $\mathrm{CO}_{2}$ se tornou uma questão urgente na indústria de aço como medida preventiva contra o aquecimento global [8].

Ao observarmos a emissão de PCDD/Fs seus níveis de emissão também foram reduzidos, uma das maneiras de diminuirmos esses níveis de emissão é manter esse material a temperaturas elevadas, onde a cinética de degradação é maior que a de formação e isso também pôde ser observado com as simulações [3]. Como a mistura permanece a uma temperatura elevada por um período mais longo, devido à técnica de recirculação dos gases de saída, é possível reduzir esses níveis de emissão.

$\mathrm{Na}$ Figura 3 podemos visualizar o perfil um perfil básico de temperatura (característico do processo) e os respectivos casos alternativos. Observando a Figura 3A verificamos que os perfis de temperatura (Cenários Base e 1), mantiveram-se normais, característico do processo, como esperado apesar do aumento do comprimento da esteira. Quando foi feito o deslocamento do forno de ignição (Cenário 2) como mostra a Fig. 3B, observamos um deslocamento no perfil de temperatura, fato que esta relacionado ao deslocamento do forno de ignição. A Figura 3C mostra o perfil de temperatura com recirculação dos gases de saída, com temperatura em torno de $100^{\circ} \mathrm{C}$ (Cenário 3 ), ao analisarmos tal fato verificamos um pequeno alargamento do perfil de temperatura em relação ao Cenário 2 . A Figura 3D, assim como a Figura 3C, mostra o perfil de temperatura com recirculação dos gases de saída, porém com temperatura em torno de $200^{\circ} \mathrm{C}$ (Cenário 4), onde foi observado um maior alargamento do perfil de temperatura em relação ao Cenário 3 . $\mathrm{Na}$ Figura 3E temos a recirculação dos gases de saída com a temperatura em torno de $300^{\circ} \mathrm{C}$ (Cenário 5), como esperado a frente de combustão sofreu um maior alargamento em relação ao Cenário 4, devido a temperatura elevada dos gases de saída. No Cenário 6 , mantivemos a recirculação dos gases de saída com temperatura em torno de $400^{\circ} \mathrm{C}$.

* Contribuição técnica ao 44ํ Seminário de Redução de Minério de Ferro e Matérias-primas, 15 Simpósio Brasileiro de Minério de Ferro e $2^{\circ}$ Simpósio Brasileiro de Aglomeração de Minério de Ferro, 15 a 18 de setembro de 2014, Belo Horizonte, MG, Brasil. 
Ao analisarmos a Figura $3 \mathrm{~F}$, observamos um alargamento da frente de combustão em relação ao Cenário 4. Da mesma maneira, no Cenário 7 (Figura 3G), o perfil de temperatura gerado pelo modelo permanece similar ao do Cenário 6 porém com um pequeno alargamento da frente de combustão (temperatura $\sim 500^{\circ} \mathrm{C}$ ).

Observou-se que, quanto maior a temperatura do gás de recirculação no processo, maior o deslocamento da curva, proporcionando o alargamento da frente de combustão, como é visto na Figura 4. Com isso proporcionamos melhor aglomeração devido ao maior tempo de residência do material na temperatura de sinterização.

O processo de sinterização é usado para fundir parcialmente e agregar os finos de minério de ferro, de maneira que sua resistência mecânica dependerá da quantidade e tipo de material fundido entre as partículas. A resistência mecânica do sínter influência a produtividade da sinterização, uma vez que uma baixa resistência mecânica resulta numa alta taxa de reciclagem de finos. Com o aumento do tempo de residência do material a elevada temperatura, aumentamos a resistência mecânica do material, devido a maior quantidade de materiais fundidos. E por consequência, a produtividade do processo devido à menor quantidade de finos, entretanto deve se evitar a formação de fases vítreas que fragilizam o material [6]. 

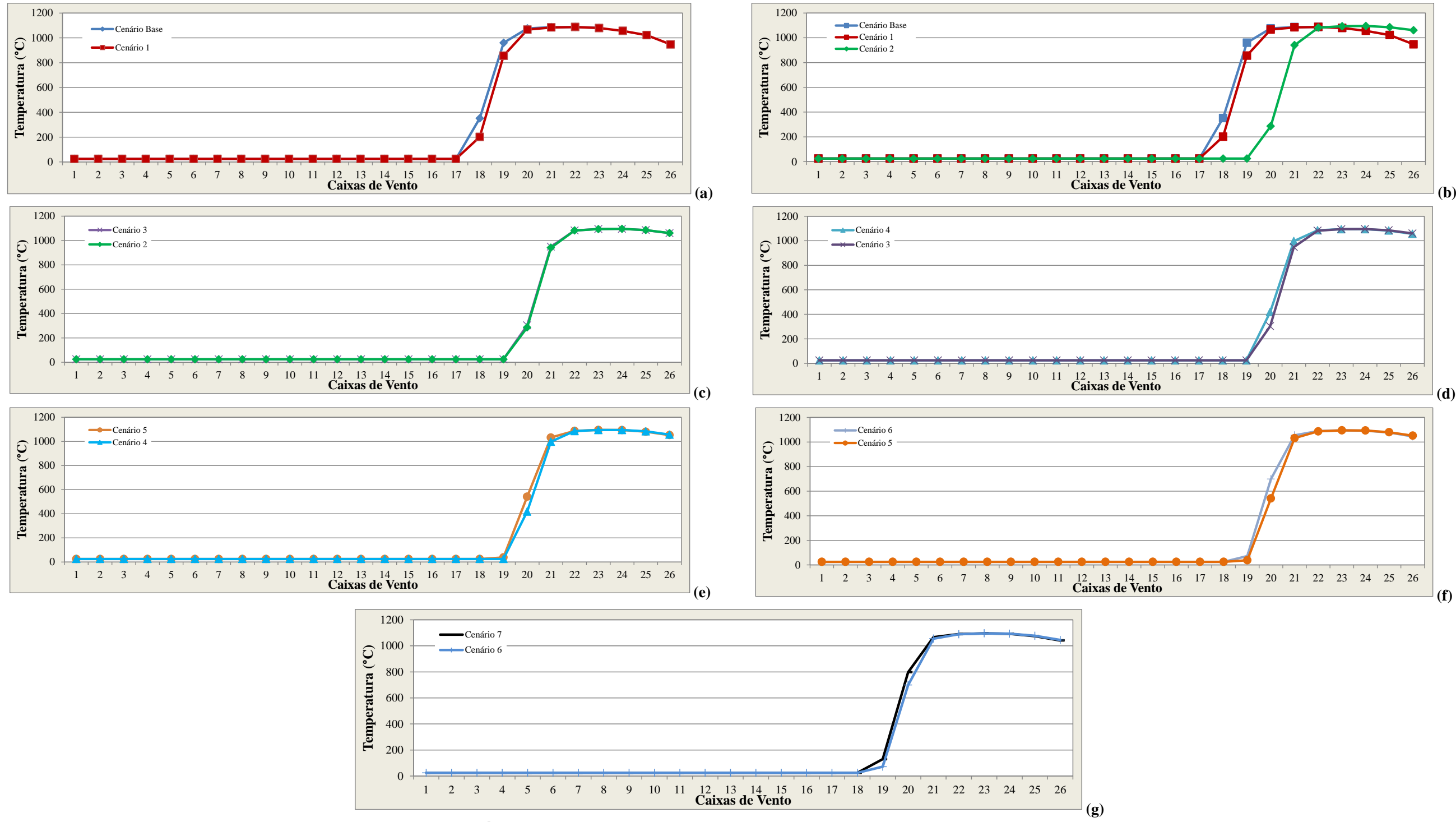

Figura 3 - Valores de temperatura previsto pelo modelo.

* Contribuição técnica ao 44 Seminário de Redução de Minério de Ferro e Matérias-primas,

Brasileiro de Aglomeração de Minério de Ferro, 15 a 18 de setembro de 2014, Belo Horizonte, MG, Brasil. 

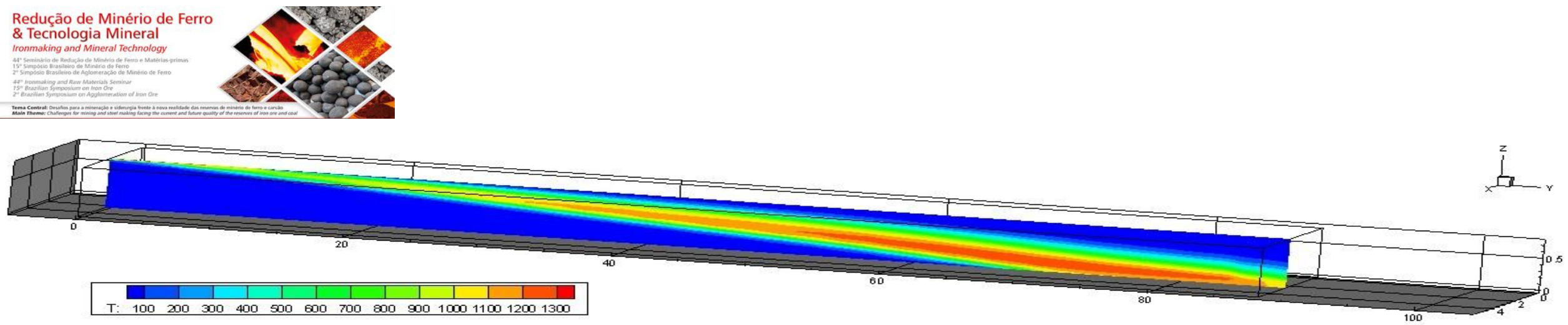

(a)

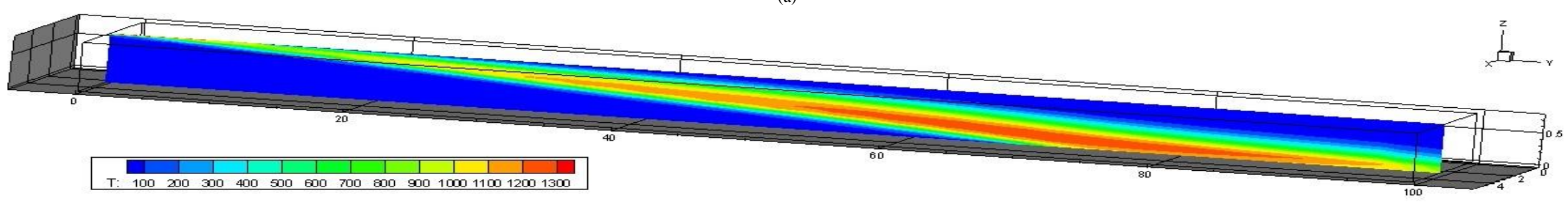

(b)

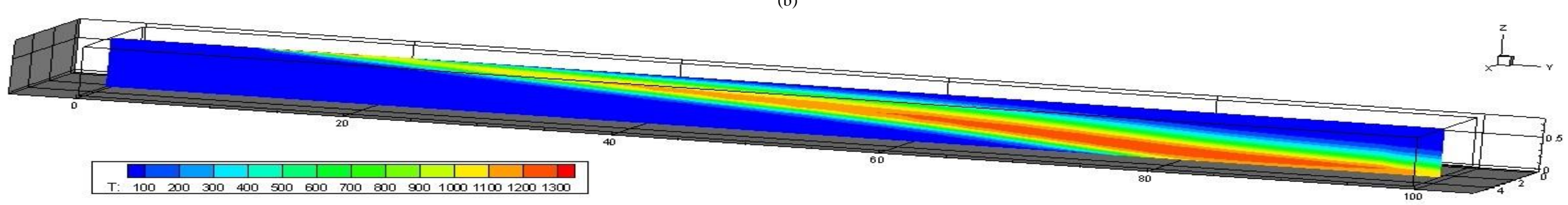

(c)

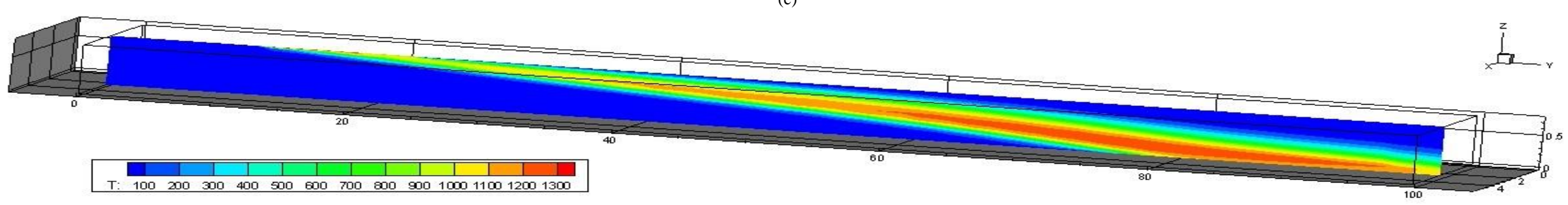

(d)

* Contribuição técnica ao 44 Seminário de Redução de Minério de Ferro e Matérias-primas, Brasileiro de Aglomeração de Minério de Ferro, 15 a 18 de setembro de 2014, Belo Horizonte, MG, Brasil. 

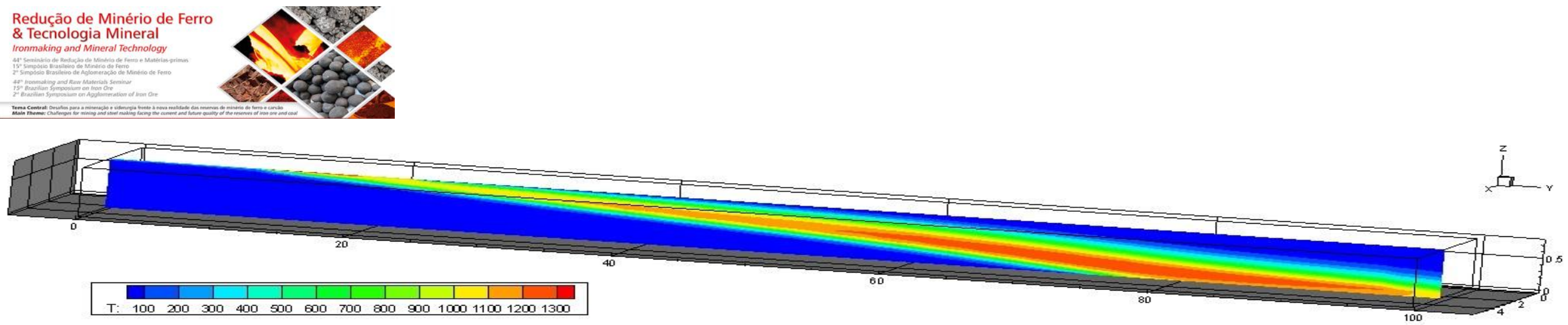

(e)

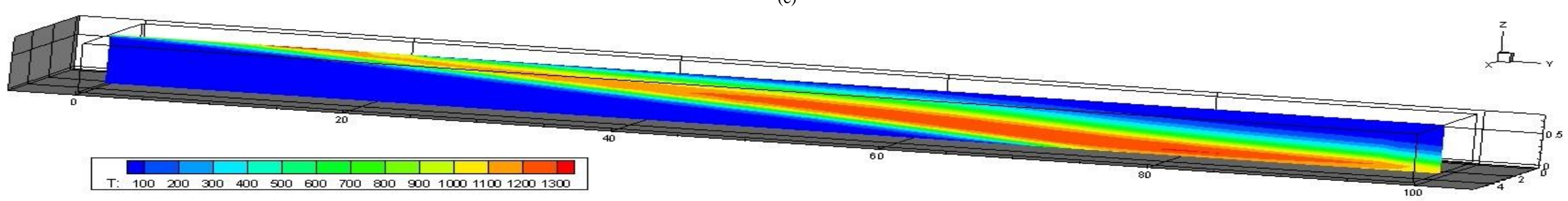

(f)

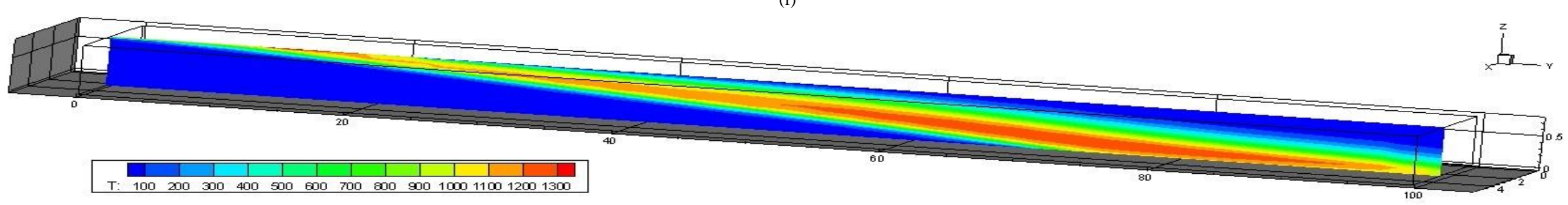

(g)

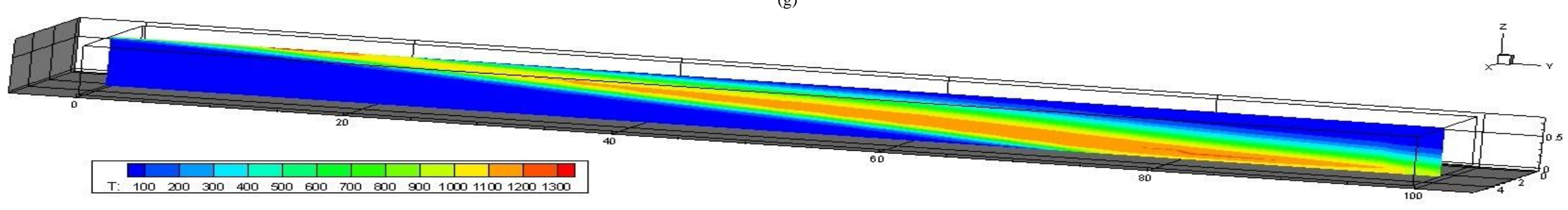

(h)

Figura 4 - Frente de combustão prevista pelo modelo.

* Contribuição técnica ao 44 Seminário de Redução de Minério de Ferro e Matérias-primas,

Brasileiro de Aglomeração de Minério de Ferro, 15 a 18 de setembro de 2014, Belo Horizonte, MG, Brasil.

15ํㅗㄴ Simpósio Brasileiro de Minério de Ferro e 2 Simpósio 


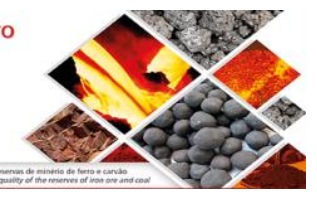

Este artigo teve por finalidade investigar a influencia da recirculação dos gases de saída no processo de sinterização. O modelo é baseado em equações de momentum, energia e espécies químicas de duas fases coexistindo simultaneamente no leito de sinterização. Tendo como base os resultados de simulação são enfatizadas algumas conclusões, as quais estão apresentadas a seguir.

A recirculação dos gases de saída do processo de sinterização pode possibilitar a redução do consumo de combustível de sólido no processo de sinterização. As simulações mostraram que tal técnica proporciona um alargamento na frente de combustão proporcional a temperatura dos gases de saída, ou seja, quanto maior a temperatura do gás de saída, maior a espessura da frente de combustão. Assim como Guilherme [5], tal processo, por consequência, aumenta a fração de cálcio-ferrita no sínter, melhorando a redutibilidade do mesmo. Esse aumento do tempo de residência do material à elevada temperatura, proporciona maior formação de fase líquida e por consequência, maior produtividade do processo, pois, dessa forma, haverá melhor aglomeração, aumentando a resistência mecânica do sínter.

Outro aspecto importante a ser destacado está relacionado com a emissão de $\mathrm{CO}_{2}$, pois o presente trabalho apresenta resultados que mostram que a recirculação dos gases de saída, no processo de sinterização, reduz a emissão de $\mathrm{CO}_{2}$, fato importantíssimo nos dias atuais devido ao efeito estufa. Da mesma forma o efeito da recirculação dos gases é benéfico em relação à emissão de PCDD/Fs devido ao alargamento da zona de alta temperatura.

\section{Agradecimentos}

Ao suporte financeiro concedido pela Coordenação de Aperfeiçoamento de Pessoal de Nível Superior (CAPES) e Universidade Federal Fluminense (UFF) que forneceu toda estrutura necessária para a realização deste trabalho.

\section{REFERÊNCIAS}

1 Geerdes M, Toxopeus H, Vliet CVD. Modern Blast Furnace Ironmaking - An Introduction. ljmuiden, 2004.

2 Castro JÁ, Nogami H, Yagi J. Numerical investigation of co-injection of pulverized coal and natural gas to the with oxygen enrichment. ISIJ International, 2002; 42(11): 1203-11.

3 Guilherme VS. Estudo da emissão de dioxinas e furanos na planta de sinterização. Dissertação de Mestrado. Volta Redonda: UFF, Jun. 2010.

4 Patankar SV. Numerical Heat Transfer and Fluid Flow. Washington: Hemisphere Publishing Company, 1985. 197p

5 Guilherme VS, Castro JA. Utilização de gás de coqueria na sinterização de minério de ferro. REM: R. Esc. Minas, Ouro Preto, 65(3), 357-362, jul. set, 2012.

6 Castro JA, França AB, Guilherme VG, Sazaki Y. Estudo numérico da influência de propriedades de amolecimento e fusão na cinética de formação de $\left(\mathrm{CaFe}_{2} \mathrm{O}_{4}-\mathrm{Ca}_{2} \mathrm{Fe}_{2} \mathrm{O}_{5}\right)$ na sinterização de minério de ferro. Tecnol. Metal. Mater. Miner. 2013; 10(1): 16-17.

7 Guilherme VS, França AB, Castro JA. Utilização de gás combustível na sinterização de minério de ferro. In: $41^{\circ}$ Seminário de redução de minério de ferro \& tecnologia mineral, Vila Velha, ES, 2011.

8 Oyama N, Iwami Y, Yamamoto T, Machida S, Higuchi T, Sato H. Development of secondaryfuel injection technology for energy reduction in the iron ore sintering process. ISIJ International, 2011; 51(6): 913-921. 